\title{
Carbetocin versus Misoprostol in Reducing Blood Loss during Cesarean Section in low risk patients. A Randomized Controlled Trial \\ Original Article

\author{
A. Moustafa' ${ }^{1}$ S. Abd Elhady', H. Shalaby ${ }^{2}$ W. Elrefaie ${ }^{3}$ \\ Department of Obstetrics and Gynecology, Faculty of Medicine, ' Nabarou Central Hospital, \\ ${ }^{2}$ Mansoura University, ${ }^{3}$ Port Said University, Egypt
}

\begin{abstract}
Aim: This study aimed to compare the use of misoprostol to carbetocin in reducing blood loss during cesarean section in low risk patients.

Materials and Methods: This randomized controlled study enrolled 300 patients who were eligible. 150 women received carbetocin100ug i.v intra-operative immediately after extraction of the fetus during cesarean section (group A). They were compared to 150 women who received misoprostol $600 \mathrm{ug}$ rectally immediately before sterilization during caesarean section (group B).

Results: There is significant difference in intraoperative uterine atony [3 $(2.0 \%)$ vs $11(7.3 \%) P<0.02]$ and the need for blood transfusion $[2(1.2 \%)$ vs $10(6.7 \%) P>0.018]$ and surgical hemostatic measures as uterine artery ligation and uterine compression sutures $[0.00$ vs $3.00(2 \%) \quad P<0.00$ and 0.00 vs $12.00(8 \%) P<0.00]$ were higher in misopristol group. Also, the need for other uterotonic drugs was significantly higher in misopristol group $(10.0 \pm 0.0$ vs $13.15 \pm 5.28, P<0.001$ and the difference in hemoglobin and hematocrit values before and after delivery were slightly higher in misopristol group with no statistical significance $(10.71 \pm 0.98$ vs $10.86 \pm 0.84, P<0.15$ and $33.86 \pm 2.8$ vs $34.29 \pm 2.7, P<0.17)$.
\end{abstract}

Conclusion: Intravenous therapy infusion of $100 \mathrm{ug}$ carbetocin reduced but no significantly blood loss during cesarean section than 600ug rectal misoprostol.

Key Words: Carbetocin, cesarean section, oxytocin, postpartum hemorrhage

Received: 09 May 2020, Accepted: 02 August 2020

Corresponding Author: Waleed El-Refaie, Department of Obstetrics and Gynecology, Faculty of Medicine, Port Said University, Port Said City 42511, Egypt, Tel.: 01224515318, E-mail: wrefaie@yahoo.com

ISSN: 2090-7265, August 2020, Vol.10, No. 3

\section{INTRODUCTION}

Cesarean section is one of the most common surgeries practiced for save delivery of the fetus, however it is not a safe route of delivery its incidence is rising especially in high and middle income countries ${ }^{[1]}$. Although the WHO recommended cesarean section rate between 10 to $15 \%$ to decline the maternal mortality ratio and neonatal mortality ratio $^{[1]}$, the incidence show sharp increase especially in Egypt to reach $52 \%$ of all deliveries ${ }^{[2]}$. The major concern is that the average blood loss during cesarean delivery is $487 \mathrm{ml}$ as estimated by Duthie $1992^{[3]}$. This amount is too close to the definition of postpartum hemorrhage by WHO as loss of $500 \mathrm{cc}$ of blood in the first 24 hours after delivery ${ }^{[4]}$ making control of blood loss during cesarean delivery crucial to decrease maternal morbidities.

Many medications used to decrease blood loss especially placental site bleeding during cesarean section including oxytocin, ergometrine, synthetic prostaglandins and recently carbetocin.
Carbetocin is an oxytocin analogue containing eight amino acids. It binds to oxytocin receptors expressed on uterine muscles of pregnant women inducing tetanic uterine contractions for about 11 minutes after administration of 8-30ug intravenous followed by rhythmic uterine contractions that last for 60 to 120 minutes (Attilakos G. et al., 2010) ${ }^{[5]}$. Also, it has a longer half life time than oxytocin and the recommended dose100ug IV ${ }^{[6]}$.

Misoprostol is synthetic analogue to prostaglandin which is cheap heat stable uterotonic making it the alternative of choice to intravenous oxytocin in low resources countries ${ }^{[7]}$. The recommended dose for prophylaxis against postpartum hemorrhage is $600 \mu \mathrm{g}$ while $800 \mu \mathrm{g}$ is used as a treatment ${ }^{[8]}$.

In the lack of sufficient studies comparing the use of carbetocin to misoprostol to decrease blood loss during cesarean section, this study was to compare the use of misoprostol to carbetocin in reducing blood loss during cesarean section. 


\section{PATIENTS AND METHODS}

This was a randomized trial study conducted at Obstetrics and Gynecology Department, Mansoura University Hospitals during the period between February 2017 to February 2018 and included 300 pregnant ladies.

Each patient signed on informed consent after thorough explanation of the process and purpose of the study, before participating in the study. Each patient had the right to withdraw from the study at any phase, without any adverse impact on her medical or ethical management.

The study was approved by the Ethical Research Committee of the Obstetrics and Gynecology Department and institutional review board in Mansoura University.

Three hundred pregnant women attended Obstetric Outpatient Clinics and Emergency Unit for Cesarean Section and considered low risk for intrapartum and postpartum hemorrhage were eligible for the study. The following patients were excluded from the study:

-Patients with previous history of postpartum hemorrhage.

-Multiple pregnancies.

-Patients with hypertension, preeclampsia and eclampsia.

-Patients with heart, renal or liver disorders.

-Diabetes mellitus and gestational diabetes patients.

-Patients with low lying placenta, placenta Previaaccreta, percreta and accidental hemorrhage.

- Cases of ante partum hemorrhage and cases with coagulation disorders were excluded from the study.

The patients were randomly assigned into 2 groups : Group A included pregnant ladies who received papal $100 \mathrm{mg}$ i.v intra-operative immediately after extraction of the fetus and group B included pregnant ladies who received misoprostol $600 \mathrm{mg}$ rectally immediately before sterilization during caesarean section.

Randomization was done through sealed envelopes containing computer generated numbers and picked up by the pregnant ladies and were offered to them by the outpatient clinic and delivery ward nurses.
All participants were subjected to thorough history taking, general and abdominal examination, obstetric ultrasound examination and laboratory investigations including complete blood count (HBG and HCT before and after 24 hours of delivery, liver functions (SGOT, SGPT, serum albumin and total bilirubin), blood glucose level, serum creatinine and coagulation profile.

All patients were delivered by cesarean section under general anesthesia. Patients in group A received carbetocin 100ug i.v (PABAL 100 micrograms/ml solution for injection, Ferring Pharmaceuticals Ltd) intra-operative immediately after extraction of the fetus; while, patients in group B received misoprostol 600ug (cytotec 200ug tablet, Pfizer G.D. Searle LLC) rectally immediately before sterilization during caesarean section.

The measures outcome of this study were the need for blood products transfusion, the amount of blood products transfusion, the operative time, operative complications uterine atony, the need for surgical interventions to stop bleeding as uterine artery ligation and uterine compression sutures and the deficit in hemoglobin level.

\section{STATISTICAL ANALYSIS}

Qualitative data was described using number and percent. Quantitative data was described using mean standard deviation for parametric data after testing normality using Kolmogrov-Smirnov test. Significance of the obtained results was judged at the $5 \%$ level. Student t-test for parametric quantitative variables was applied to compare between the two studied groups. Paired t-test for parametric quantitative variables was done to compare between the two periods (pre-post). Pearson correlation was used to correlate between continuous parametric variables. Median and range was used for non-parametric quantitative data and Chi square was used to test significance. For all above-mentioned statistical tests done, the threshold of significance is fixed at 5\% level ( $p$-value). The results were considered non-significant when the probability of error is more than $5 \%(p>0.05)$, significant when the probability of error is less than $5 \%(p<0.05)$ and highly significant when the probability of error is less than $0.1 \%(p<0.01)$. 
Study flow chart:

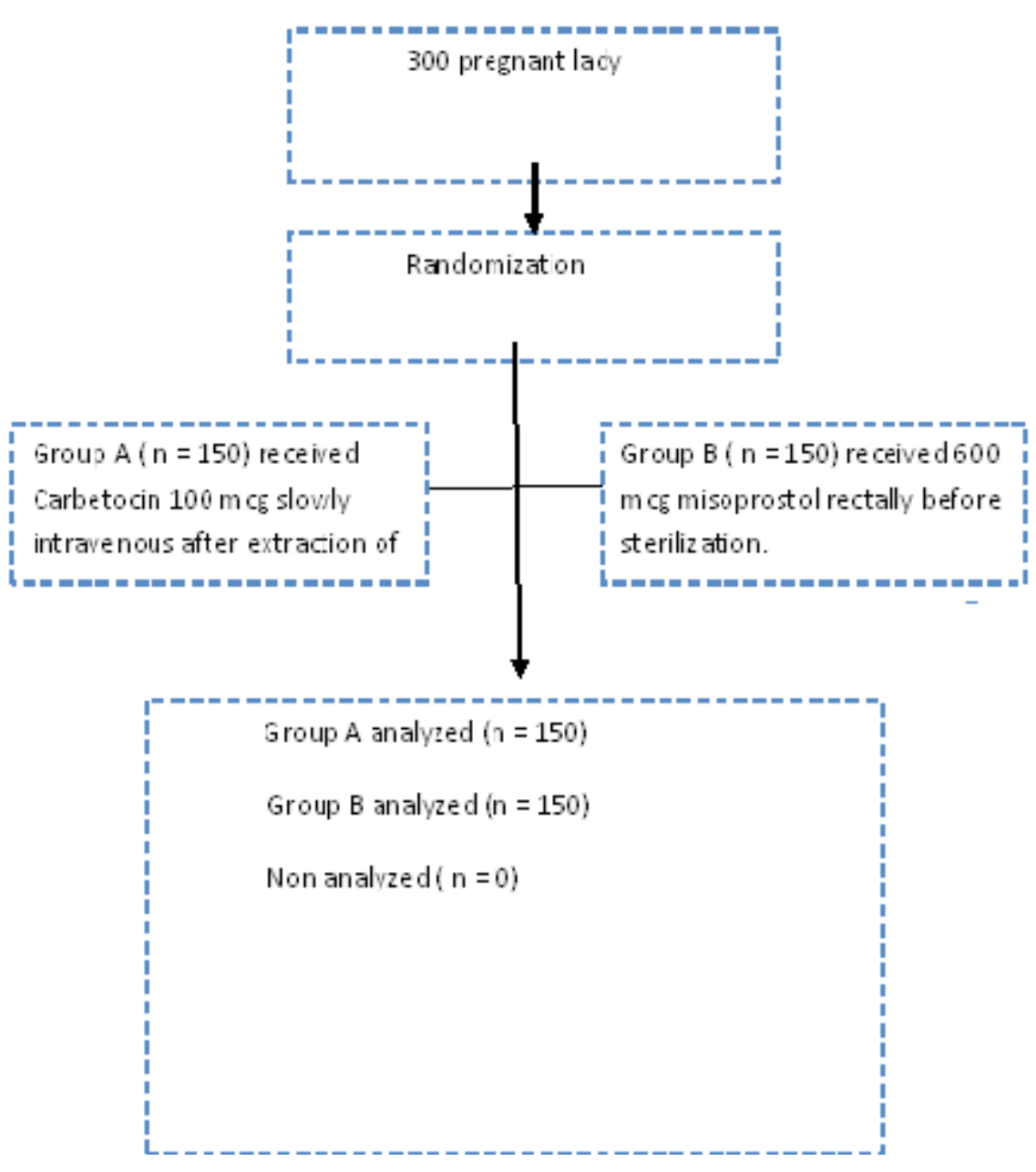

\section{RESULTS}

A total of 300 women who underwent CS were included in the study. In 150 women, carbetocin 100 $\mathrm{mg}$ was given intravenous intra-operative immediately after extraction of the fetus (group A) and in the other 150 women misoprostol 600 ug was given rectally immediately before sterilization during caesarean section (group B). The demographic characteristics of both groups are presented in Table 1 .

As regard the intraoperative characters of both groups presented in Table 2, the duration of operation was average of 50 minutes in both groups without statistically significant difference. The intraoperative surgical difficulties as adhesion was not statistically different in both groups [50 (33.3\%) vs 48 (32.0\%)
$P<0.8$ ]. However, intraoperative uterine atony was significantly higher in misoprostol group [3 $(2.0 \%)$ vs $11(7.3 \%), P<0.02]$ and the need for blood transfusion was significantly higher in misopristol group [2 $(1.2 \%)$ vs $10(6.7 \%), P>0.018]$ and surgical hemostatic measures as uterine artery ligation and uterine compression sutures were significantly higher in misopristol group $[0.00$ vs $3.00(2 \%) P<0.00$ and 0.00 vs $12.00(8 \%), P<0.00]$.

The need for other uterotonic drugs was significantly higher in misoprostol group $(10.0 \pm 0.0$ vs $13.15 \pm 5.28$, $P<0.001)$ as presented in Table 3 . The difference in hemoglobin and hematocrit values before and after delivery were slightly higher in misoprostol group with no statistical significance $(10.71 \pm 0.98$ vs $10.86 \pm 0.84$, $P<0.15$ and $33.86 \pm 2.8$ vs $34.29 \pm 2.7, P<0.17)$ as presented in Table 4. 
Table 1: Demographic Data of studied patients (age, parity and gravidity)

\begin{tabular}{|c|c|c|c|}
\hline & $\begin{array}{c}\text { Group A } \\
\mathrm{N}=150\end{array}$ & $\begin{array}{c}\text { Group B } \\
\mathrm{N}=150\end{array}$ & P value \\
\hline \multicolumn{4}{|l|}{ Age/years } \\
\hline Mean \pm SD & $28.06 \pm 4.3$ & $28.59 \pm 4.8$ & $p=0.31$ \\
\hline \multicolumn{4}{|l|}{ Gravidity } \\
\hline Median (min-max) & $2.0(1.0-6.0)$ & $2.0(1.0-5.0)$ & $\begin{array}{c}\mathrm{z}=2.23 \\
p=0.026^{*}\end{array}$ \\
\hline \multicolumn{4}{|l|}{ Parity } \\
\hline Median (min-max) & $1.0(0.0-5.0)$ & $1.0(0.0-4.0)$ & $p=0.02 *$ \\
\hline \multicolumn{4}{|l|}{ CS number } \\
\hline Median (min-max) & $1.0(0.0-4.0)$ & $1.0(0.0-4.0)$ & $P=0.51$ \\
\hline
\end{tabular}

*Statistically significant $(p<0.05)$

Table 2: Intraoperative characters: Type of anesthesia, time of operation, complications, need for medical and surgical intervention and blood transfusion

\begin{tabular}{|c|c|c|c|}
\hline & $\begin{array}{c}\text { Group A } \\
\mathrm{N}=150 \mathrm{n}(\%)\end{array}$ & $\begin{array}{c}\text { Group B } \\
\mathrm{N}=150 \mathrm{n}(\%)\end{array}$ & Pvalue \\
\hline Presence of Adhesions & $50(33.3)$ & $48(32.0)$ & $p=0.8$ \\
\hline \multicolumn{4}{|l|}{ Complications n (\%) } \\
\hline Atony & $3(2.0)$ & $11(7.3)$ & $p=0.02 *$ \\
\hline Duration of operation $/ \mathrm{min}$ & 50.0 & 50.0 & \\
\hline Median (min-max) & $(30.0-70.0)$ & $(30.0-80.0)$ & $p=0.78$ \\
\hline \multicolumn{4}{|l|}{ Unit of blood transfusion ( $\%)$} \\
\hline Received one unit. & $2(1.2)$ & $10(6.7)$ & \\
\hline Not received & $148(98.3)$ & $140(93.3)$ & $p=0.018^{*}$ \\
\hline \multicolumn{4}{|l|}{ Surgical measures (\%) } \\
\hline Uterine artery ligation & 0.00 & $3.00(2 \%)$ & $P=0.00 * *$ \\
\hline Compression sutures & 0.00 & $12.00(8 \%)$ & \\
\hline
\end{tabular}

*Statistically significant $(p<0.05)$ 
Table 3: Comparison of oxytocin dose between group A and B

\begin{tabular}{|c|c|c|c|}
\hline & $\begin{array}{c}\text { Group A } \\
\mathrm{N}=15\end{array}$ & $\begin{array}{c}\text { Group B } \\
\mathrm{N}=80\end{array}$ & $P$ value \\
\hline \multicolumn{4}{|l|}{ Oxytocin dose(iu) } \\
\hline Mean \pm SD & $10.0 \pm 0.0$ & $13.15 \pm 5.28$ & $p<0.001 * *$ \\
\hline \multicolumn{4}{|c|}{ ** High statistically significant $(p<0.01)$} \\
\hline \multicolumn{4}{|c|}{ Table 4: Comparison of hemoglobin and hematocrit values before delivery group A and B } \\
\hline \multirow[t]{3}{*}{ Before delivery } & Group A & Group B & \\
\hline & $\mathrm{N}=150$ & $\mathrm{~N}=150$ & Pvalue \\
\hline & Mean \pm SD & Mean \pm SD & \\
\hline Hemoglobin (mg/d10) & $10.71 \pm 0.98$ & $10.86 \pm 0.84$ & $p=0.15$ \\
\hline Hematocrit & $33.86 \pm 2.8$ & $34.29 \pm 2.7$ & $p=0.17$ \\
\hline
\end{tabular}

$P$ value significant if $(\mathrm{P}<0.05)$

\section{DISCUSSION}

Cesarean section is a delivery by abdominal and uterine incision and should be performed only if there is risk to the fetus or the mother from vaginal delivery, increase cesarean section practice especially for non-medical causes carry many short-term risks to the mother as postpartum hemorrhage, blood transfusion, hysterectomy and maternal death ${ }^{[9-11]}$. In the era of increase cesarean section rate especially in Egypt, many efforts should be done to decrease maternal morbidities for instance decreasing blood loss and the need for blood transfusion.

Many studies worldwide compared misoprostol to oxytocin in reducing blood loss during cesarean section, for example Gupta P. et al. (2016), who found that misoprostol is effective as intramuscular oxytocin in reducing blood loss during cesarean section, however it has more side effects as regarding transient pyrexia and shivering ${ }^{[12]}$.

Also Adanikin Al et al. (2014) who compared oxytocin infusion to $600 \mathrm{ug}$ rectal misoprostol after cesarean section in tropical climates where there is little capability for refrigeration, found that misoprostol is as effective as oxytocin infusion for prevention of $\mathrm{PPH}^{[13]}$ and Nagasree M.G.S and Athota Smitha (2013) compared misoprostol to oxytocin in prevention of PPH concluded that misoprostol is cost effective, easily administrated and can be considered for use in low resource areas ${ }^{[14]}$.

There are few studies compared carbetocin to misoprostol in reducing blood loss during cesarean section, but there is abundance of studies compared the use of carbetocin to the use of oxytocin and the use of misoprostol to the use of oxytocin in reducing blood loss after cesarean section and prevention of $\mathrm{PPH}$.

This randomized controlled study aimed to compare the use of intra-partum misoprostol to carbetocin for decreasing blood loss during cesarean section and subsequently decreasing risk of postpartum hemorrhage. In this study, low risk patients for postpartum hemorrhage including previous four deliveries or less, unscarred uterus or previous one cesarean section, elective cesarean sections and no medical disorder complicating pregnancy were selected. Although general anesthesia is known as a risk factor to uterine atony and postpartum hemorrhage in cesarean section ${ }^{[15,16]}$, it is the preferred type of anesthesia by most of the patients in this community that is why all patients in this study received general anesthesia, this made patients in both group at equal risk of uterine atony during cesarean section.

There was no significant difference regarding the operative time in both groups but the uterine atony evident by the presence of floppy uterus after delivery 
of the fetus and placenta and significant placental site bleeding was significantly more frequent in misoprostol group $11(7.3 \%)$ patients compared to carbetocin group $2(3 \%)$ patients. This is mostly attributed to the potent uterotonic effect of carbetocin as evident in previous study by D. Cordovani and his coworkers who found that in carbetocin reduce incidence of uterine atony in low risk patients ${ }^{[17]}$.

Uterine atony which was more significant in the misoprostol group necessitate additional surgical procedure to control bleeding such as uterine artery ligation in $3(2 \%)$ patients and uterine compression sutures in $8(11 \%)$ patients. This is in agreement with Ali AE-NAE-G et al. (2017) who found that carbetocin decreases the need for surgical measures to decrease blood loss during operation ${ }^{[18]}$.

In the present study, the need for blood transfusion was significantly higher in misoprostol group. This can be explained by the less number of patients with uterine atony in carbetocin group. This was in agreement with Ali AE-NAE-G et al. (2017) who found that carbetocin decreases the need for blood transfusion after cesarean ${ }^{[18]}$. Also, uterine atony which was more significant in the misoprostol group necessitate use of more oxytocin, this agrees with (Sull, Chong YS, Samuel M 200) who concluded that carbetocin significantly decreases the need for other uterotonic drugs ${ }^{[19]}$.

In this study, the usage of carbetocin during cesarean delivery decreased but not significantly the amount of intraoperative blood loss evident by lower hemoglobin and hematocrit deficit. However, this insignificant difference is due to estimating the blood loss based on deficit in hemoglobin level pre and postoperative as the sufficient data about number of towels used and the amount of blood in surgical suctions during cesarean delivery is lacked. This finding agrees with Sitaula S. et al. (2017) who found that carbetocin was superior to misoprostol in decreasing intraoperative blood loss ${ }^{[20]}$.

\section{LIMITATIONS OF THE STUDY}

The limitations in this study are the relatively small number of patients and that the study was not blinded, so randomized controlled trial including larger number of patients and multicenter studies are recommended for clear reliable conclusion and adequate measurement of blood loss during the cesarean delivery.

\section{CONCLUSION}

In this study, i.v. infusion of 100 ug carbetocin in cesarean section after delivery of the fetal shoulder is superior to $600 \mathrm{ug}$ rectal misoprostol at the time of anesthesia induction during cesarean section in reducing blood loss and subsequent maternal morbidities.

\section{ETHICS APPROVAL AND CONSENT TO PARTICIPATE}

This research was approved by the ethical committee (Postgraduate Study and Research Committee) Faculty of Medicine Port Said University. The reference number of ethical committee approval is not applicable as the committee in the faculty is recently established. Because this study is retrospective, formal consent was not required. However, a written informed consent was obtained from each woman before performing any procedure.

\section{CONFLICT OF INTEREST}

There are no conflicts of interests.

\section{REFERENCES}

1. World Health Organization. Statement on Caesarean Section Rates. (http://apps.who.int/iris/ bitstream/106651/161442//WHO_RHR_15.02 eng.pdf) Accessed 12 Apr 2016.

2. El-Zanaty, F. and A. Way. 2015. Egypt Demographic and Health Survey 2014. Cairo: Ministry of Health and Population, El-Zanaty and Associates, and Macro International.

3. Duthie SJ, Ghosh A, Ng A, Ho PC.. Intraoperative blood loss during elective lower segment caesarean section. British Journal of Obstetrics and Gynaecology 1992;99:364-7.

4. World Health Organization. Managing complications in pregnancy and childbirth. Geneva: World Health Organization, 2000.

5. Attilakos G, Psaroudakis D, Ash J, et al. Carbetocin versus oxytocin for the prevention of postpartum haemorrhage following caesarean section: the results of a double-blind randomised trial.BJOG:An International Journal of Obstetrics \& Gynaecology 2010;117: (8), 929-936.

6. Dansereau J, Joshi AK, Helewa ME, et al. Doubleblind comparison of carbetocin versus oxytocin in prevention of uterine atony after cesarean section. American Journal of Obstetrics and Gynecology 1999;180: (3), 670-676. 
7. McCormick ML, Sanghvi HC, Kinzie B, McIntosh N. Preventing postpartum hemorrhage in low-resource settings. Int J Gynaecol Obstet 2002;77: 267-75

8. World Health Organization. Cesarean section without medical indication increases risk of shortterm adverse outcomes for mothers. Geneva: WHO. Available from: http://whqlibdoc.who. int/hq/2010/WHO_RHR_HRP_10.20_eng.pdf. Accessed 21 Mar $20 \overline{0} 15$.

9. Souza JP, Gulmezoglu A, Lumbiganon P, Laopaiboon M, Carroli G, Fawole B,et al. Caesarean section without medical indications is associated with an increased risk of adverse shortterm maternal outcomes: the 2004-2008 WHO global survey on maternal and Perinatal health. BMC Med 2010;8:71.

10. Villar J, Carroli G, Zavaleta N, Donner A, Wojdyla $\mathrm{D}$, Faundes A, et al. Maternal and neonatal individual risks and benefits associated with caesarean delivery: multicentre prospective study. BMJ 2007;335(7628):1025.

11. Rossen J, Okland I, Nilsen OB, Eggebo TM. Is there an increase of postpartum hemorrhage, and is severe hemorrhage associated with more frequent use of obstetric interventions? Acta Obstet Gynecol Scand 2010;89:1248-55.

12. Gupta P, Sunita J \& Shekhar C. Misoprostol versus Oxytocin in Prevention of Postpartum Hemorrhage. J Androl Gynaecol 2016;4: (1), 4.

13. AdanikinAI, OrjiE,AdanikinPO, et al. Comparative Study of Rectal Misoprostol to Oxytocin Infusion in Preventing Postpartum Haemorrhage After Caesarean Section. Nepal Journal of Obstetrics and Gynaecology 2014;8: (2).

14. Nagasree M.G.S and Athota Smitha. MISOPROSTOL VERSUS OXYTOCIN IN PREVENTION OF POSTPARTUM
HEMORRHAGE. International Journal of Basic and Applied Medical Sciences 2015; Vol. 5 (1) January-April, pp. 180185-/Nagasree and Smitha

15. Zhang J, Troendle J, Reddy UM, Laughon SK, Branch DW, Burkman R, Landy HJ, Hibbard JU, Haberman S, Ramirez MM, Bailit JL, Hoffman MK, Gregory KD, Gonzalez-Quintero VH, Kominiarek M, Learman LA, Hatjis CG, van Veldhuisen P. Contemporary cesarean delivery practice in the United States. Am J Obstet Gynecol 2010;203:326 e1-e10.

16. World Health Organization. recommendations for the management of the third stage of labor and community perceptions and actions on postpartum haemorrhage: findings from a national survey in Ethiopia. Geneva: World Health Organization; 2007.

17. Cordovani D, Balki M, Farine D, et al. Carbetocin at elective Cesarean delivery: a randomized controlled trial to determine the effective dose. Canadian Journal of Anesthesia/Journal canadien d'anesthésie 2012;59: (8), 751-757.

18. Ali AE-NAE-G, Nasr AAM, Ahmed HH, et al. Carbetocin versus Oxytocin and Misoprostol in prevention of atonic post-partum hemorrhage in high risk patients planed for cesarean delivery. International Journal of Reproduction, Contraception, Obstetrics and Gynecology 2017;7: (1), 10

19. Su L-L, Chong Y-S \& Samuel M. Carbetocin for preventing postpartum haemorrhage. Cochrane Database of Systematic Reviews.2012,John Wiley \& Sons, Ltd.

20. Sitaula S, Uprety DK, Thakur A, et al. Impact of Preoperative Rectal Misoprostol on Blood Loss during and after Elective Cesarean Delivery: A Randomized Controlled Trial. Nepal Journal of Obstetrics and Gynaecology 2017;11: (2), 37. 